\title{
Ferrocifen derivatives that induce senescence in cancer cells: selected examples
}

Céline Bruyère $^{\mathrm{a}, \mathrm{b}, 1}$, Véronique Mathieu ${ }^{\mathrm{a}, 1, \square}$, Anne Vessières ${ }^{\mathrm{c}, \mathrm{d}}$, Pascal Pigeon ${ }^{\mathrm{b}, \mathrm{c}, \mathrm{d}}$, Siden Top ${ }^{\mathrm{c}, \mathrm{d}}$, Gérard Jaouen ${ }^{\mathrm{b}, \mathrm{c}, \mathrm{d}}$, Robert Kiss ${ }^{\mathrm{a}}$

${ }^{a}$ Laboratoire de Cancérologie et de Toxicologie Expérimentale, Faculté de Pharmacie, Université Libre de Bruxelles, Brussels, Belgium

${ }^{\mathrm{b}}$ Chimie ParisTech, 75005 Paris, France

${ }^{\text {c }}$ Sorbonne Universités, UPMC Univ Paris 06, IPCM UMR 8232, F-75005 Paris, France

${ }^{\mathrm{d}}$ CNRS, UMR 8232, IPCM, F-75005 Paris, France

Keywords: Metallodrug, Ferrocene, Anti-cancer effects, Senescence, Cytokine

Corresponding author at: Laboratoire de Cancérologie et Toxicologie Expérimentale, Faculté de Pharmacie, Université Libre de Bruxelles (ULB), Campus de la Plaine, Boulevard du Triomphe, 1050 Brussels, Belgium. Tel.: +32 477317 388. E-mail address: vemathie@ulb.ac.be (V. Mathieu).

${ }^{1}$ The first two authors contributed equally to the work.

\begin{abstract}
Platinum coordination complexes represent an important class of anti-tumor agents. Due to recognized drawbacks, research into other types of metallodrugs has been diversified with the aim of finding new chemical entities with alternative mechanisms of action to overcome
\end{abstract}


classical chemoresistance. P5 and DP1, two closely related ferrocenyl complexes bearing a similar ferrocenyl-ene-phenyl motif and displaying marked differences in their conformations and oxidation state versatility, were assayed in cancer cell models characterized by various sensitivities to pro-apoptotic stimuli. P5 and DP1 exert growth inhibitory effects between 0.5 and $10 \mu \mathrm{M}$ against glioma and melanoma cells including pluripotent stem-like cells. These effects are due, at least partly, to senescence induction with typical SA- $\beta$-galactosidase staining and senescence-associated secretory phenotype (SASP) as measured by the secretion of IL- $1 \alpha$, IL-1 $\beta$, IL-6, IL-8 and TNF- $\alpha$. Regulation of these cytokines' secretion may be related to AP-1 and other transcription factors unrelated to senescence. An in vivo graft of B16F10 cells after in vitro pre-incubation with DP1 or P5 led to increased survival in mice. In conclusion, P5 and DP1 ferrocenyl complexes induce senescence in various cancer cell models associated with distinct sensitivity to pro-apoptotic stimuli.

\section{Introduction}

Organometallic complexes of arsenic played an important role, particularly at the start of the twentieth century, in the treatment of incurable illnesses of the time [1]. An iconic example includes Paul Ehrlich's development of Salvarsan ${ }^{\circledR}$, one of the first key treatments for syphilis, a disease from that period that could be compared to AIDS today. In the course of developing this molecule, Ehrlich introduced the concept of chemotherapy, which is thus historically associated with an organometallic entity that is an entity containing a direct metalcarbon or similar bond [1]. During the 1960s, the discovery by Rosenberg [2] of the antitumoral properties of the coordination complex cisplatin, soon to be followed by carboplatin and oxaliplatin, proved to be an innovation in anti-cancer metallodrugs. At the moment, these complexes of platinum, either alone or in combination, are used in more than 
$70 \%$ of treatments. However, due to resistance problems and serious, particularly renal, secondary effects, and a fairly narrow range of application, research into other types of metal complexes has developed. This research has progressed, in particular, from an exploration of the coordination complexes of $\mathrm{Ru}$ with NAMI-A and KP1019 to an examination of the organometallic species of this metal [3-6].

The covalent nature of transition metals, resulting in strong metal-carbon bonds, and the space-filling nature and versatility of their oxidation states compared to those of the principal groups, have supported the development of new organometallic chemistry for medical applications. Among the usable organometallic complexes, iron complexes are distinctive due to the abundance of this metal in the body and the particular nature of ferrocene, which is a compact and stable aromatic metallocene with unique redox properties. In fact, this entity has been widely used with varied success for biomedical purposes [7]. Among these compounds, ferroquine (FQ) was synthesized in 1997 [8] and reached phase II clinical trials, and the ferrocifen family was developed by some of us starting in 1996 [9-11].

The current study characterizes the antitumor activity of two of these ferrocifen derivatives, P5 and DP1 (Fig. 1Aa and Ab). P5 is 1,1-di(4-hydroxyphenyl)-2-ferrocenyl-but1-ene [12], DP1 is 1-(di-4-hydroxyphenyl-methylidenyl)-[3]ferrocenophane [13], and both are prepared from a McMurry coupling reaction between propanoylferrocene or [3]ferrocenophanone, respectively, with dihydroxybenzophenone. While P5 could lead to the formation of quinone methide due to an electronic delocalization from the iron to the phenol group [14], the electron could stay in the iron environment in the case of DP1, due to the ansa C3 bridge constraint.

Nevertheless, this study highlights that these two compounds induce similar cellular and molecular phenotypic changes related to senescence induction in various cancer cell models. 
Forcing cancer cells to enter into senescence may represent an interesting therapy to stabilize cancer patients as discussed below [15].

\section{Materials and methods}

\subsection{Cell lines and compounds}

Human glioma Hs683 (ATCC code HTB-138) and U373 (ECACC code 08061901) cells and mouse melanoma B16F10 (ATCC code CRL-6475) cells were cultivated in RPMI culture medium supplemented with $10 \%$ of heat inactivated fetal bovine serum and antibiotics as previously described [16].

DP1 [13] and P5 [12] were synthesized in our laboratory as previously described.

\subsection{MTT colorimetric assay}

MTT (3-(4,5-dimethyl-2-thiazolyl)-2,5-diphenyl-2H-tetrazolium bromide) assays were conducted once in sextuplicate over a $72 \mathrm{~h}$ period of treatment as previously described [16] except for the recovery MTT assay. For this assay, the cells were treated in $25 \mathrm{~cm}^{2}$ flasks with $10 \mu \mathrm{M}$ of DP1 or P5 for $72 \mathrm{~h}$ or left untreated (control). Treated or control cells were then seeded in 96 well plates and allowed to grow for 1, 2, 3, 4, 6 and 8 days without any additional treatment. The absorbance of the control cells measured on day 1 was arbitrarily normalized to $100 \%$.

\subsection{Clonogenic assay}


Soft agar clonogenic assays were performed as previously described [16]. A minimum of 10 pictures per experimental condition were quantified, measuring the area covered by the clones after 4 weeks of culture. Each experiment was conducted once in triplicate.

Aa

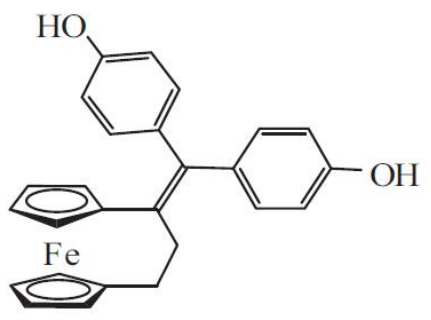

DP1

Ba

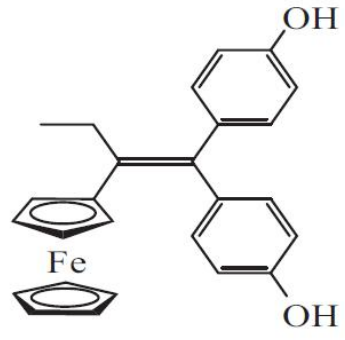

P5
Ab

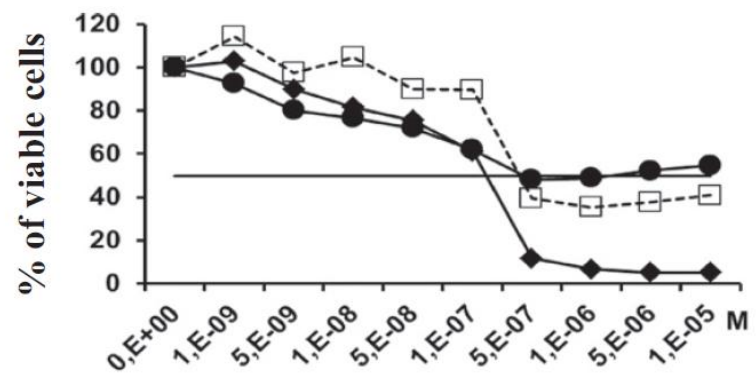

Bb

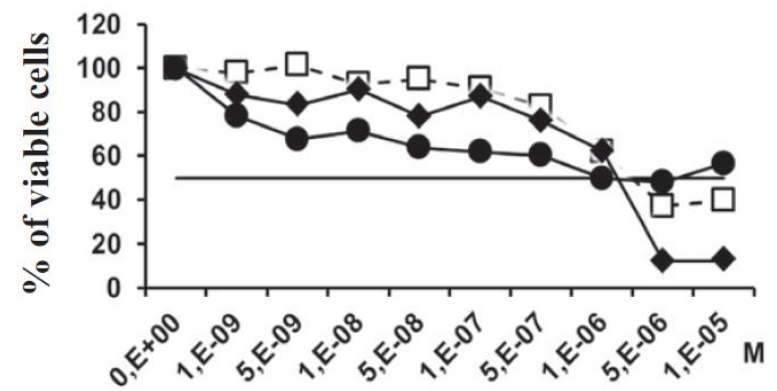

Cb

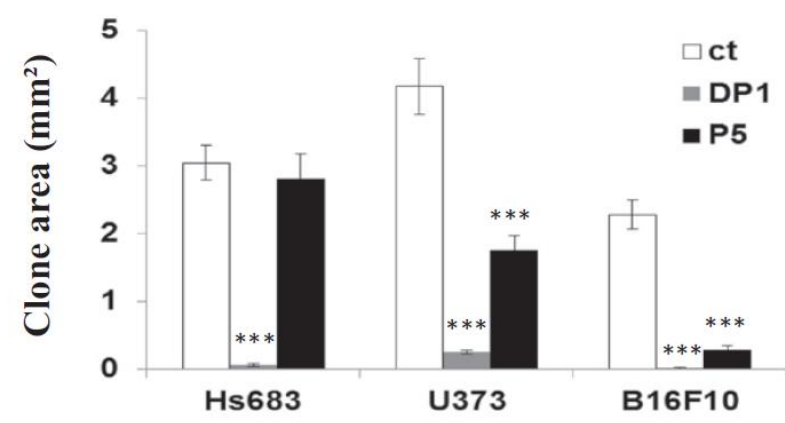

Fig. 1. Ferrocenes inhibit the global growth of cancer cells. Ab: Dose-response curves of three cancer cell models treated with DP1 obtained by the colorimetric MTT assay after $72 \mathrm{~h}$ of treatment (Aa). White squares: Hs683 human glioma cells; black dots: U373 human glioma cells; black diamonds: B16F10 mouse melanoma cells. Bb: MTT dose-response curves of the cellular models treated with P5 (Ba). C: Ca: Illustrations of Hs683 clones that developed after 4 weeks in the control versus DP1-treated conditions. Cb: Quantification of the area covered by the clones per field in the 3 cell line models after 4 weeks of culture in the absence or presence of DP1 or P5 at $1 \mu \mathrm{M}$. Data are presented as the mean \pm SEM of a minimum of 10 fields and a maximum of 20 fields per experimental condition.

\subsection{Senescence induction measurements}


Senescence induction was evaluated through senescence associated (SA) $\beta$-galactosidase staining as previously described and according to the manufacturer's instructions (SigmaAldrich, Diegem, Belgium) [17]. The staining was performed $72 \mathrm{~h}$ after a $72 \mathrm{~h}$ period of treatment with DP1 or P5.
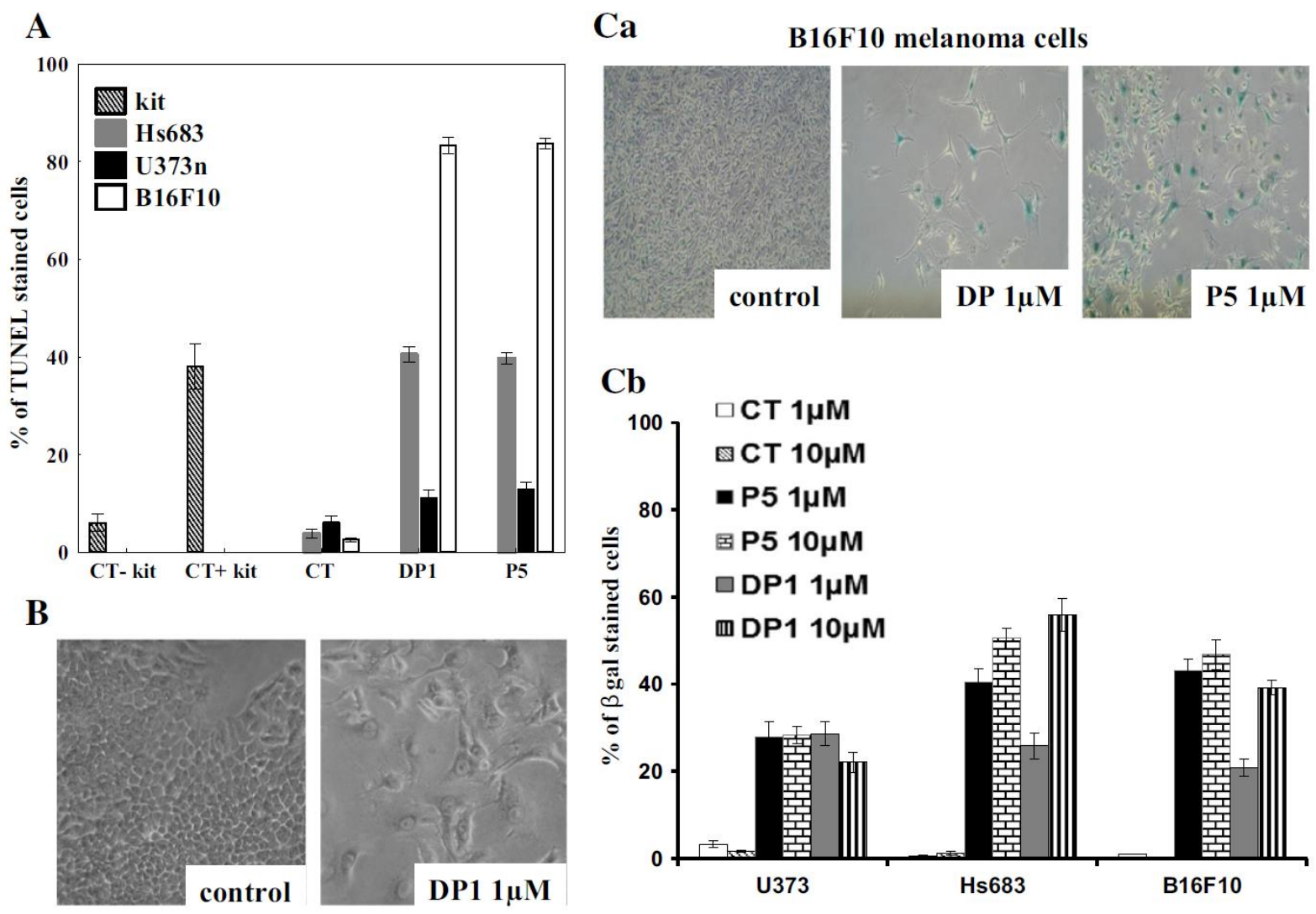

Fig. 2. The anti-cancer effects of ferrocenes relate mainly to senescence rather than to apoptosis induction. A: The percentages of cells stained using the TUNEL technique after 72 h of treatment with $10 \mu \mathrm{M}$ of DP1 or P5. The results are presented as the mean \pm SEM of four replicates. B: Morphological illustration of Hs683 cells left untreated or treated with $1 \mu \mathrm{M}$ DP1 for $72 \mathrm{~h}$. Treated cells are enlarged and flat. C: SA- $\beta$-galactosidase staining: Ca: Illustrations of typical staining obtained in B16F10 cells $72 \mathrm{~h}$ after a 3 day period of treatment. $\mathrm{Cb}$ : Quantification of the percentage of green-blue stained cells (dark/black in the gray scale printed version) in panel Ca. Data are presented as the mean \pm SEM of 10 fields per experimental condition. 
Apoptosis induction was evaluated once in quadruplicate through TUNEL staining with the APO-AF kit following the manufacturer's recommendations (BD Laboratories, Erembodegem, Belgium) [18].

\subsection{Western blotting}

p53, p21, $\alpha$-tubulin and GAPDH expression levels were determined by western blot as previously described [17]. GAPDH (glyceraldehyde 3-phosphate dehydrogenase; dilution 1:2000) and p53 (dilution 1:250) antibodies were purchased from Cell Signaling (Leiden, The Netherlands), p21 (dilution 1:300) from BD (Erembodegem, Belgium) and $\alpha$-tubulin (dilution 1:1000) from Abcam (Cambridge, UK).

\subsection{Cytokine secretion analysis}

After $72 \mathrm{~h}$ of treatment with DP1 or P5, cell culture supernatants were collected. The assay was performed according to the manufacturer's instructions with the Mosaic ${ }^{\mathrm{TM}}$ ELISA Human Cytokine Panel 1 kit (R\&D Systems, \#MEA001, Oxon, United Kingdom). The concept of this assay is based on classical ELISA (enzyme-linked immunosorbent assay) techniques. The assay allows the simultaneous quantitative determination of 8 different cytokines in a single sample through multiplex microarray technology. The microplate was placed into the imager for luminescence detection (BioRad ${ }^{\circledR}$ ChemiDoc ${ }^{\mathrm{TM}}$ XRS Imager). The results were analyzed using Quansys Q-View ${ }^{\mathrm{TM}}$ Software from R\&D Systems.

\subsection{General and AP-1 transcription factor activity measurements}

The analysis of the activation status of transcription factors in treated versus control cells was conducted with a Protein/DNA Combo Array from Panomics (Paris, France). The membrane array is spotted with specific complementary DNA sequences to the specific 
consensus DNA sequences of 385 transcription factors. Nuclear protein extracts were prepared from control and $1 \mu \mathrm{M}$ DP1 or P5 treated U373 cells (3 h of treatment) with the Panomics kit following the manufacturer's instructions. Each nuclear extract is then incubated with a mix of biotin-conjugated consensus DNA sequences of the 385 transcription factors. After separation of the complexes from the free probes, the samples are incubated with the membrane to allow hybridization. Revelation with HRP-streptavidin allows highlighting the activated transcription factors present in each sample.

Similar procedure has been conducted for activated AP-1 members' determination with the AP-1 transcription factor assay (TransAM AP-1 Family, Active Motif). After $3 \mathrm{~h}$ of treatment with $1 \mu \mathrm{M}$ or $10 \mu \mathrm{M}$ of $\mathrm{DP} 1$ or $\mathrm{P} 5$, nuclear proteins were extracted using the nuclear extraction kit from Active Motif (Rixensart, Belgium) according to the manufacturer's instructions. The first step of the AP-1 transcription factor assay is the binding of AP-1 complexes of the samples to their consensus sequence. After a $1 \mathrm{~h}$ incubation, the detection of the different AP-1 complex members bound to DNA consensus sequences was performed with specific antibodies (phospho-c-jun: 1/500, c-Fos: 1/1000, FosB: 1/1000, Fra-1: 1/1000, JunB: 1/1000, and JunD: 1/1000). An HRP-conjugated secondary antibody (dilution: 1/1000) was used and revealed by colorimetry. Absorbance was read on a spectrophotometer at 450 $\mathrm{nm}$ (reference wavelength: $655 \mathrm{~nm}$ ).

\subsection{In vivo experiment}

B16F10 cells were cultured in vitro in the presence or absence of DP1 or P5 for three days before being grafted into the flank of mice; 200,000 cells per mouse were grafted. The tumor size was measured three times per week with a caliper. The mice were sacrificed when the tumors reached $450 \mathrm{~mm}^{2}$ for ethical reasons. This experiment was performed after 
authorization (LA1230568) from the Federal Department of Health, Nutritional Safety and Environment (Belgium) and the Ethical Animal Committee.

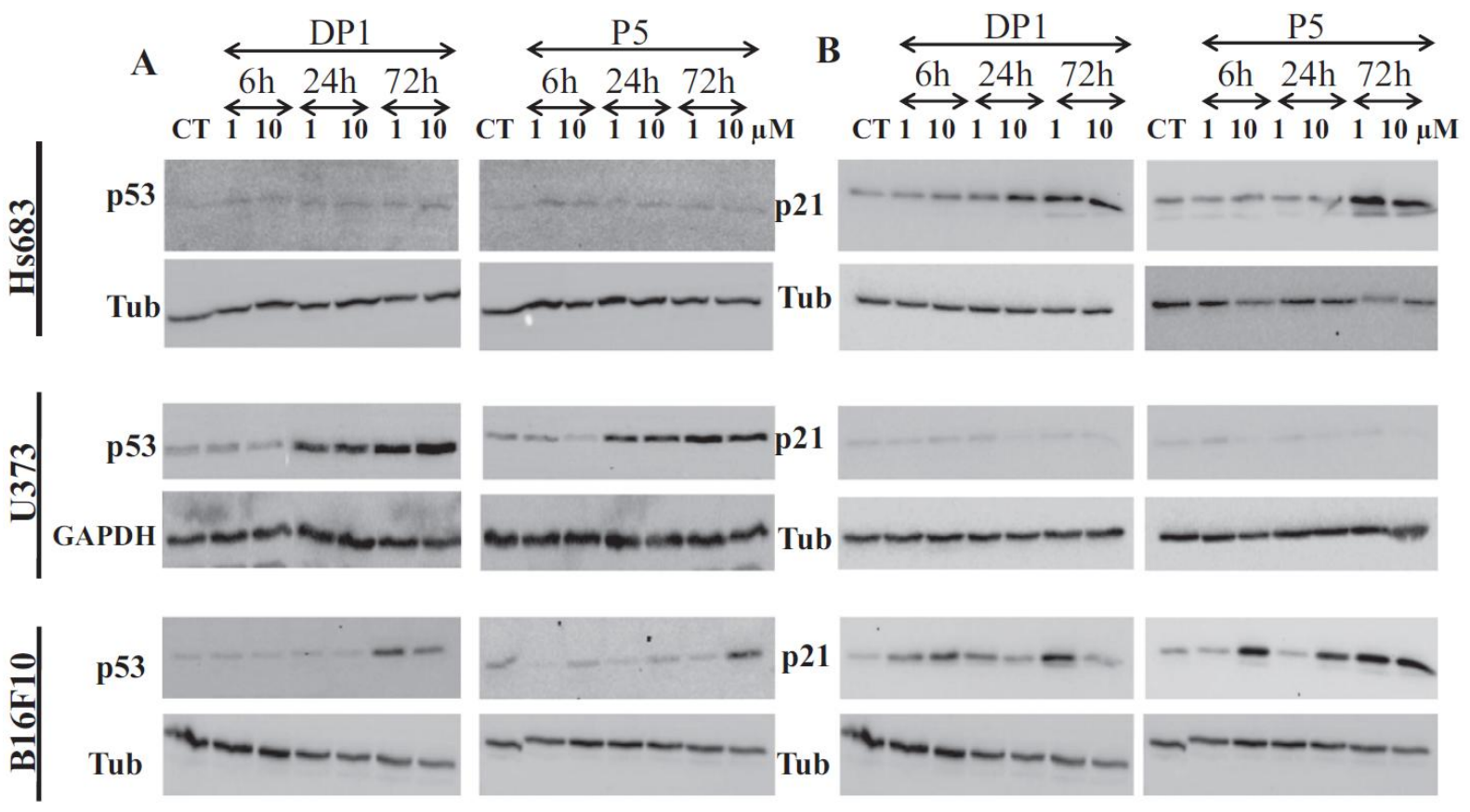

Fig. 3. The analysis of the effects of ferrocenes on the p53/p21 senescence pathway. p53 (A) and p21 (B) expression levels were evaluated by western blot in the three cell line models over time.

\section{Results}

3.1. DP1 and P5 ferrocenyl derivatives affect differentiated and pluripotent cancer cell global growth properties

The anti-cancer effects of DP1 and P5 were first assayed using a colorimetric MTT assay in three cancer cell models, U373 and Hs683 human glioma and B16F10 mouse melanoma cell lines. These models were chosen because they display different levels of sensitivity to several chemotherapeutic apoptosis-inducing stimuli [18-20]. Dose-response curves for each cell line treated with DP1 (Fig. 1Ab) or P5 (Fig. 1Bb) clearly showed that i) DP1 reached 
$50 \%$ of growth inhibition at a concentration as low as 0.1 to $0.5 \mu \mathrm{M}$ while P5 reached this level at approximately 1 to $5 \mu \mathrm{M}$, and ii) that increasing the compound's concentration, at least up to $10 \mu \mathrm{M}$, did not improve the growth inhibitory effects of DP1 or P5 in the case of the glioma models, whose dose-response curves are characterized by a "plateau" phase at approximately $50 \%$ of viable cells, while the percentage of $\mathrm{B} 16 \mathrm{~F} 10$ cells remaining viable when exposed to increased compound concentration decreased to $10 \%$. One explanation among others for this "plateau" phase could be related to the selective effects of the compounds on a subset of the cell population: the insensitive or less sensitive cells, which leads to a renewal of the cell population. Therefore, we wondered if these compounds exert any effects on pluripotent cancer cells. Clonogenic assays performed in soft agar revealed that $1 \mu \mathrm{M}$ of DP1 or P5 significantly decreased the clones' development in the three cancer cell models except for P5 in the case of Hs683 cells (Fig. 1C) for which a $10 \mu \mathrm{M}$ concentration was needed to impair their development (data not shown). P5 appeared less potent than DP1 in all of the cellular models, a feature previously observed in the MTT colorimetric assay.

\subsection{DP1 and P5 are potent senescence inducers associated with apoptosis in some models}

only

Apoptosis induction was evaluated through TUNEL staining in the three cellular models exposed to $10 \mu \mathrm{M}$ of DP1 or P5 for $72 \mathrm{~h}$. Fig. 2A shows that both compounds induced more than $80 \%$ of apoptosis in the B16F10 cells while we found approximately $40 \%$ of apoptotic cells in the Hs683 DP1- or P5-treated cells and less than 15\% of apoptosis in the U373 glioma model. Considering the very similar growth inhibitory dose-response curves of Hs683 and U373 to DP1 and P5 in the MTT assay (Fig. 1A and B), apoptosis induction does not seem to be the sole and unique mechanism by which DP1 and P5 decrease the viable cell population by $50 \%$. 
A marked increase in cell size and flat morphology of treated cells (Fig. 2B: Hs683) could be indicative of senescence. Fig. 2C confirms that both DP1 and P5 induced between 25 and $60 \%$ of senescence, depending on the cellular model and the dose. Senescence appears thus as a common feature induced by these two compounds in all three cancer models in contrast to apoptosis observed in only some of the models. p53 expression was found to be increased by DP1 and P5 treatments in both U373 and B16F10 models (Fig. 3A). p21, a downstream p53 target and potent senescence inducer [21,22], was also investigated and found to be increased in the Hs683 and B16F10 models only (Fig. 3B) but without any correlation to p53 expression. DP1- and P5-induced senescence could thus be mediated by p21 induction in Hs683 and B16F10 models independent of p53 while the pathways involved in U373 senescence induction remain to be deciphered. Indeed, no p16 expression, another major senescence-associated protein $[21,22]$, could be detected in any of the three cellular models left untreated or treated with the compounds (data not shown).

A

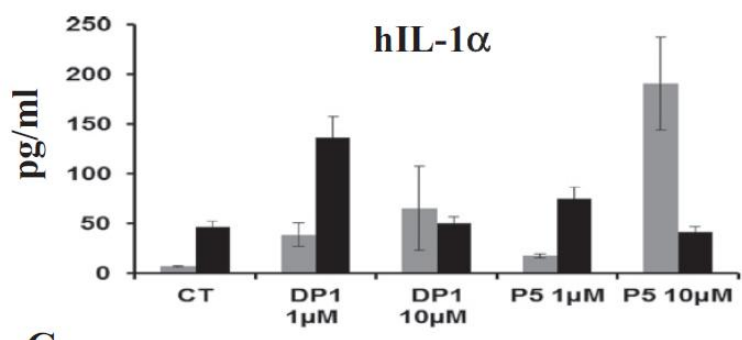

C
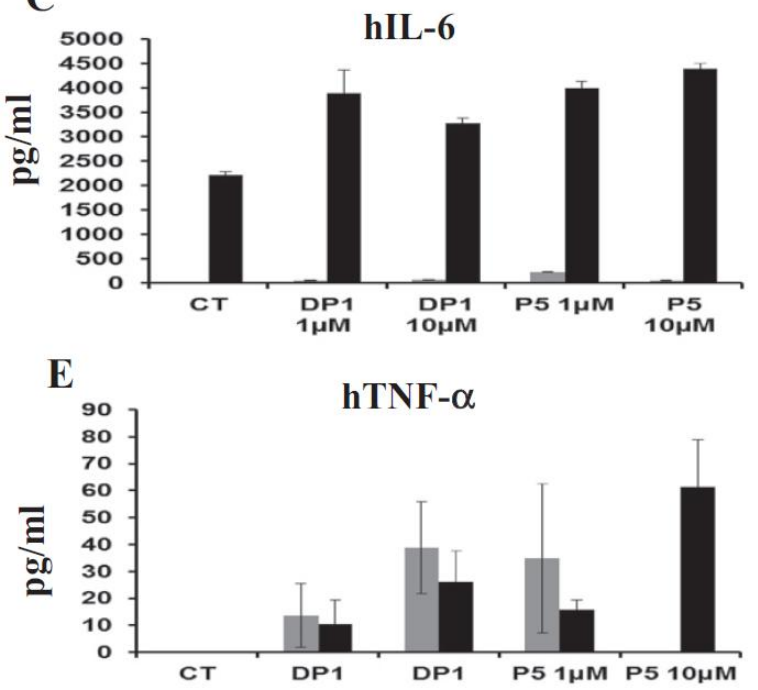

B
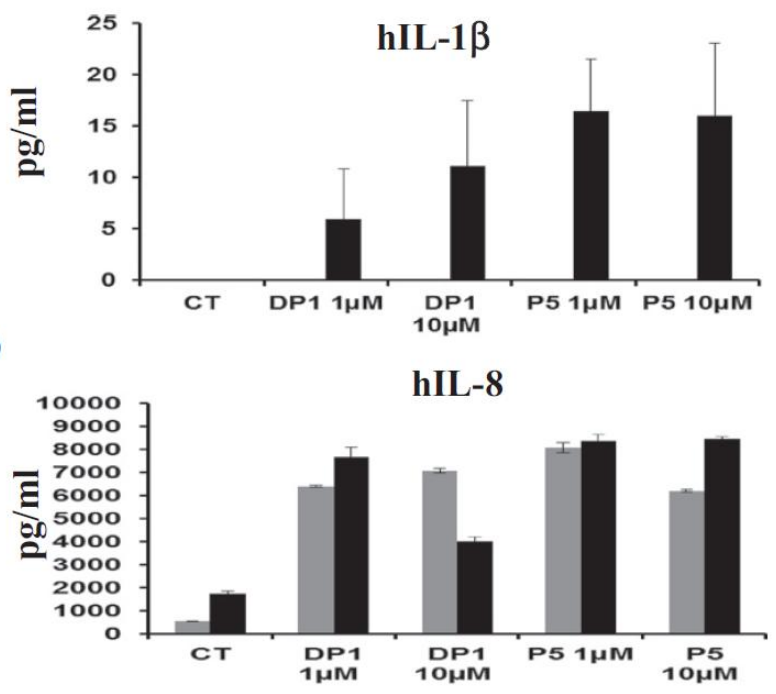

$\mathbf{F}$

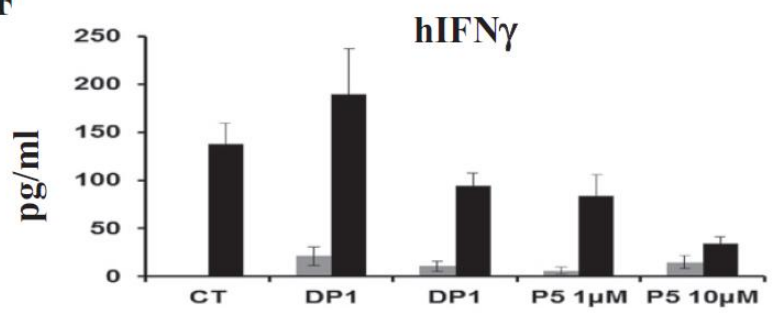


Fig. 4. Evidence of a typical SASP in DP1 and P5 treated cancer cells. Secreted cytokine concentrations were evaluated through mosaic ELISA. The results are expressed for Hs683 (gray columns) and U373 (black columns) as the mean \pm SEM of four replicates per experimental condition. Data were normalized by the number of cells from which the supernatants were analyzed.

\subsection{Ferrocenyl derivative-induced senescence displays senescence-associated secretory}

phenotype (SASP)

Senescence has recently been characterized by an inflammatory response comprised of specific cytokines that can differentiate senescence from cell cycle arrest [22-26]. SASP has thus been investigated in Hs683 and U373 models after $72 \mathrm{~h}$ of treatment (Fig. 4). Secreted IL-8 and TNF- $\alpha$ were increased in both treated cell lines while IL- 6 and IL-1 $\beta$ were found to be secreted and/or induced only in U373 cells. Modifications to IL- $1 \alpha$ and IFN- $\gamma$ secretion after treatment with DP1 or P5 appeared to vary with the cell line and the dose (Fig. 4A and F).

We then performed an analysis of the activated transcription factors in the control versus treated U373 cells after a $3 \mathrm{~h}$ treatment with $1 \mu \mathrm{M}$ of DP1 or P5. Interestingly, the C/EBP and NFאB families (hatched circles, Fig. 5A), known to be involved in regulating the expression of cytokines involved in senescence processes [15,25-27], were not found to be expressed nor activated in the nuclei of these cells. In contrast, we identified 10 transcription factors whose activities were markedly induced by both DP1 and P5 treatments, including antioxidant-RE, Beta-RE, PAX-4, -6 and -8, MSP-1, HFH-1 and -2, PPUR and CYP1A1 (black squares, Fig. 5A). In parallel, as the production of these cytokines has been related, at least partly, to AP-1 transcription activity in white blood cells [28,29], we investigated the effects of DP1 and P5 on AP-1 family members' activity in Hs683 glioma cells (Fig. 5B). The activity of Jun-B, -C and -D appeared to be stimulated at $1 \mu \mathrm{M}$ after $3 \mathrm{~h}$ of treatment while $10 \mu \mathrm{M}$ for $3 \mathrm{~h}$ had less 
or even inhibitory effects. No clear effects could be observed with respect to Fra-1, and an inhibition of Fos-b activity was observed only with $10 \mu \mathrm{M}$ of DP1 and P5. Fos-c was not active in Hs683 cells (data not shown).

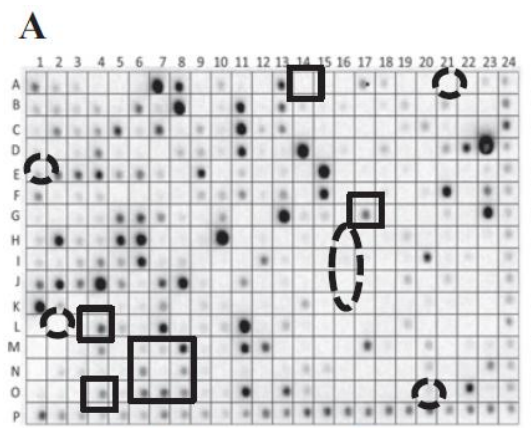

U373 control cells

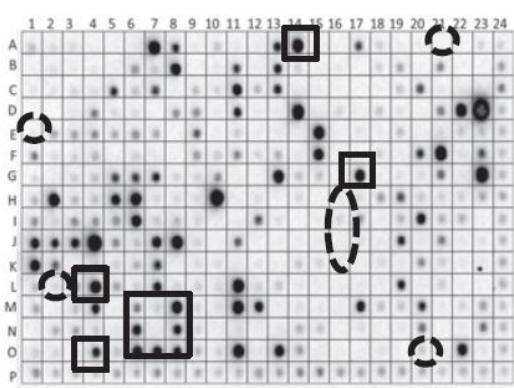

U373 1 $\mu$ M DP1 treated cells

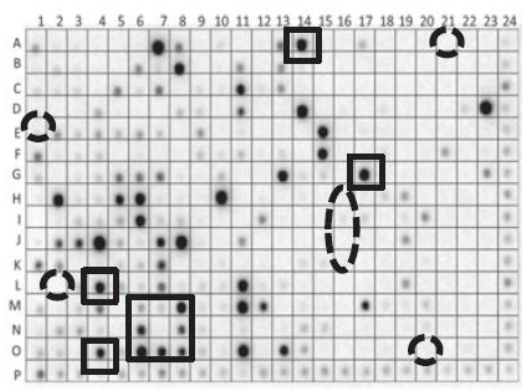

U373 1 $\mu$ M P5 treated cells

B

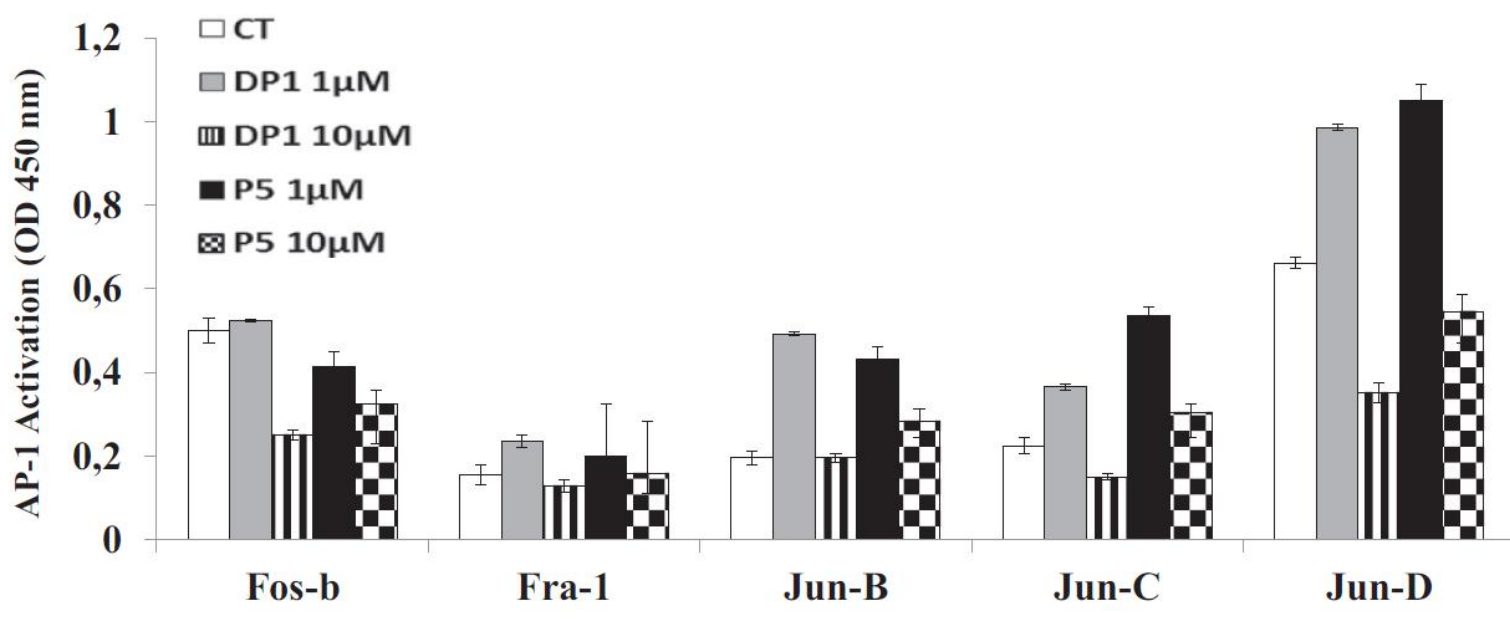

Fig. 5. The effects of ferrocenes on transcription factor activity. A: Microarrays obtained after incubation of the membranes with nuclear extracts from U373 cells left untreated or treated for $3 \mathrm{~h}$ with $1 \mu \mathrm{M}$ of DP1 or P5. Lane " $p$ " and column " 24 " contain controls while other dots correspond to the binding of one defined transcription factor to its specific DNA sequence. The arrays analyze 345 transcription factors at once. The black squares highlight the DP1- or P5-induced transcription factors while the hatched circles correspond to $\mathrm{NF \kappa B}$ binding sequences (L2, O20 and A21) and C/EBP binding sequences (E1, H16 to K16) that are known to be involved in senescence-associated transcriptional regulation of cytokine expression. B: The AP-1 activation status in Hs683 cells after $3 \mathrm{~h}$ of treatment with DP1 or P5. Data are expressed as the mean \pm SEM of four replicates.

\subsection{The irreversible characteristic of DP1- and P5-induced senescence in vitro leads to}

marked tumor growth impairment in vivo 
The treatment of B16F10 mouse melanoma cells with $10 \mu \mathrm{M}$ of DP1 or P5 for $72 \mathrm{~h}$ induced senescence as assessed above (Fig. 2). This senescence induction was not reversible, up to eight days of culture in vitro (Fig. 6A).
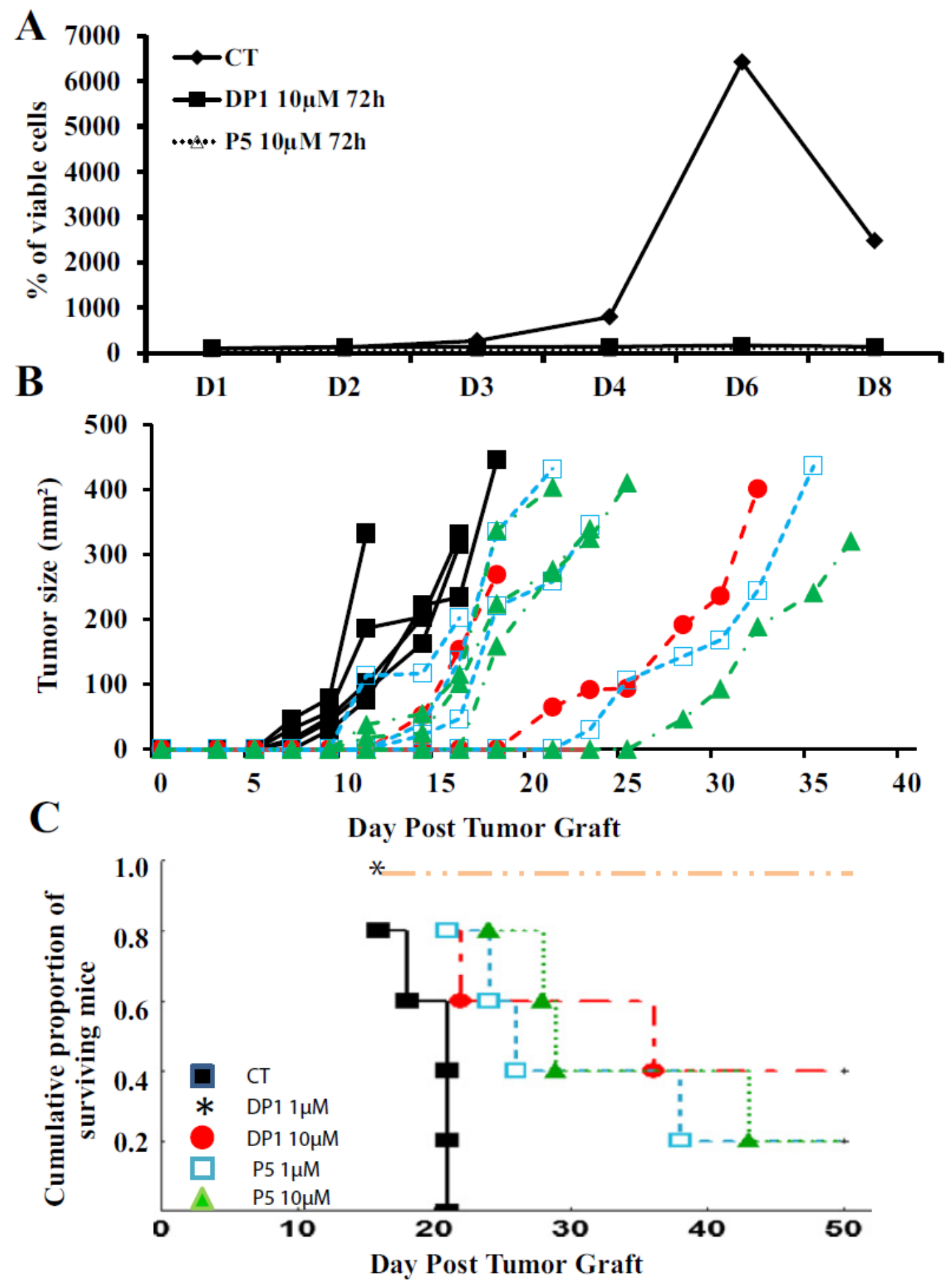

Fig. 6. A graft of treated B16F10 cells in mice results in reduced tumor take and growth and is associated with improved survival. A: In vitro growth of B16F10 cells over time after 
treatment with $10 \mu \mathrm{M}$ of DP1 or P5 for $72 \mathrm{~h}$ compared to untreated cells. B: B16F10 subcutaneous tumor growth in each mouse grafted with untreated cells (black closed squares), $72 \mathrm{~h} 10 \mu \mathrm{M}$ DP1-treated cells (red closed circles), or $72 \mathrm{~h} 1 \mu \mathrm{M}$ (blue open squares) or $10 \mu \mathrm{M}$ (green closed triangles) P5-treated cells. The same legend has been used for panel $\mathrm{C}$ which shows the survival of the mice that died due to tumor burden or had to be sacrificed due to tumors reaching an ethical size limit.

Similarly, grafting of DP1- or P5-treated B16F10 melanoma cells into the flank of mice significantly delayed tumor growth (Fig. 6B). Interestingly, no tumor growth was observed in the group of mice grafted with $1 \mu \mathrm{M}$ DP1-treated cells while $2 / 5$ mice developed tumors when grafted with $10 \mu \mathrm{M}$-treated DP1 cells (up to 40 days post-graft). Accordingly, survival of the animals was significantly improved when they were grafted with treated cells (Fig. 6C; Log Rank test $\mathrm{p}$ value $<0.01$ for the comparison of control versus DP1 $1 \mu \mathrm{M}$ groups and $\mathrm{p}<0.05$ for the comparison between the other groups and the control one).

\section{Discussion}

This study highlights that while both ferrocenyl derivatives, DP1 and P5, display significant differences in their chemical and three dimensional structures and potential reactivities, notably regarding quinone methide production, they share the ability to induce marked senescence processes in cancer cells, at least in vitro, characterized by typical morphology, SA- $\beta$-galactosidase staining and SASP (Figs. 2, 3 and 4) [21,22]. We observed for both compounds MTT assay dose-response curves characterized by a "plateau" phase around $50 \%$ in the case of glioma Hs683 and U373 cell lines while it was not the case with respect to B16F10 melanoma cells. These observations could be correlated, at least partly, to the pro-apoptotic effects of DP1 and P5 which are much higher in B16F10 cells than in Hs683 and U373 cells (Figs. 1A, B and 2A). Indeed, MTT assay reflects the mitochondrial succinate dehydrogenase metabolic activity which has been shown to be decreased in aging-associated senescence [30]. Therefore the contribution of senescence inducing effects of DP1 and P5 to MTT assay results is difficult to estimate. In particular, the senescence versus pro-apoptotic 
effects of chemotherapeutic drugs depend on dose schedule and intracellular context [31-33] with low sub-lethal dose inducing senescence while high dose can be pro-apoptotic [33]. This could explain, at least partly, why we observed no tumor formation in vivo after B16F10 in vitro treatment with $1 \mu \mathrm{M}$ DP1 (remaining cells are senescent) while the remaining living cells after $10 \mu \mathrm{M}$ DP1 treatment led to delayed tumor development (Fig. 6B). The present study highlights nevertheless senescence as a common induced feature in all cell models and more importantly with both types of compounds.

Senescence has been recognized as a promising alternative to cytotoxic compounds [32], particularly for overcoming chemoresistance [32,34,35]. Senescence is an "irreversible" proliferation arrest that represents an important shield to oncogenic transformation $[21,22,32]$. Indeed, oncogenic-induced senescence (OIS) has been observed in numerous benign human tumors, such as adenomas or naevi, impairing their neoplastic transformation [32,33]. Abundant literature also indicates that low, non-cytotoxic, doses of chemotherapeutic agents can induce senescence [33]. Interestingly, the induction of senescence was previously observed for the ferrocenyl derivative of hydroxytamoxifen [36]. This drug-induced senescence (DIS) can result from DNA damage or through an increase in reactive oxygen species (ROS) through the p53/p21 and/or p16/Rb signaling pathways, similar to OIS [36]. In our study, it is unlikely that senescence relates to ROS because their intracellular levels in Hs683 and U373 cells did not correlate with a senescence phenotype after P5 or DP1 treatment (no increase; data not shown) as previously observed in some melanomas [37]. While P5 is assumed to induce direct DNA damage [38], such an effect with respect to DP1 does not appear obvious and remains to be proven. We wonder, therefore, if these compounds could target Chk2, a key checkpoint protein that leads to G1 cell cycle arrest through p53 activation. Concentrations of DP1 and P5 able to decrease Chk2 kinase activity by $50 \%$ are of $20 \mu \mathrm{M}$ and $>100 \mu \mathrm{M}$ respectively (data not shown), forcing us to reject this hypothesis. 
Moreover, senescence could be observed in the three cellular models irrespective of p53 expression (Fig. 3). One hypothesis is that IFN-inducible cellular senescence gene IFI16 could increase p21 levels independently of p53 [39]. However, this possibility could not explain U373 senescence, which was even independent of p21 (Fig. 3). In fact, DIS occurs often regardless of i) p53 status [33,36] by example through Aurora A kinase inhibition [40] or ii) p21 activation [34]. p27 has also been involved in senescence induction [36]. This pathway still remains to be investigated.

Nevertheless, the induction of terminal differentiation, action on telomeres or stress signals through the p38/MAPK pathway represent other alternatives for DP1 and P5 mechanisms that could lead to senescence $[33,34,36]$. In particular, we showed in this study that DP1 and P5 both similarly affect AP-1 transcription factor activity (Fig. 5). The fact that stimulation of AP-1 occurs mainly at $1 \mu \mathrm{M}$ and not at $10 \mu \mathrm{M}$ fits with our in vivo results: no tumors were observed after 40 days when mice were grafted with $1 \mu \mathrm{M}$ DP1-treated cells while 2/5 mice developed subcutaneous tumors when challenged with $10 \mu \mathrm{M}$ DP1-treated cells (Fig. 6). Importantly, the effects of the SASP are still debated as the cytokines produced have autocrine and paracrine effects in vivo, notably affecting tumor associated fibroblast functions $[23,28,36]$. Indeed, many SASP factors, such as IL-6 or IL-8, are known to stimulate aggressive cancer properties and could favor tumorigenesis, mostly via paracrine loops $[23,26]$. Nevertheless, secreted factors could act as a positive autocrine feedback loop to reinforce and maintain senescence $[23,28,36]$. Similarly, the pro-inflammatory environment due to the SASP could facilitate cell-mediated cancer cell clearance [36]. Kinetics, dynamics and cell context must be taken into account to decipher this "intricate tapestry" [22].

Possible future uses of senescence-inducing drugs include i) stabilizing advanced cancer patients who no longer respond to cytotoxic agents because apoptosis-resistant cancers are 
still able to undergo senescence $[34,36]$ and ii) chemoprevention or treatment of premalignant and early tumors [36]. Interestingly, senescence has been described as a potential strategy to circumvent drug resistance [33-35]. The use of a pan-caspase inhibitor in neuroblastoma cells forced these cells to undergo senescence under doxorubicin treatment while at the same dose without the caspase inhibitor, doxorubicin is triggering apoptosis [31]. Similarly, senescence can be induced in doxorubicin-resistant neuroblastoma cells [41]. In particular, cathepsin L inhibition through siRNA or inhibitor was also able to reverse drug induced resistance phenotypes in various cancer cell models and drugs [41].

To achieve these purposes, the appropriate formulations for each application must be developed. Such mandatory approaches are ongoing to evaluate the therapeutic benefits of DP1 or P5 after in vivo delivery [42,43].

\section{Acknowledgments}

We thank the Agence Nationale de la Recherche (Mecaferrol, ANR-10-BLAN-0706) as well as the Belgian Brain Tumor Support (BBTS, Belgium) for their financial support. R.K. is a director of research with the Fonds National de la Recherche Scientifique (FRS-FNRS; Belgium).

\section{References}

[1] S. Gibaud, G. Jaouen, in: G. Jaouen, N. Metzler-Nolte (Eds.), Medicinal Organometallic Chemistry, Book Series: Topics in Organometallic Chemistry, vol. 32, Springer-Verlag, Berlin Heidelberg, 2010, pp. 1-20.

[2] B. Rosenberg, L. Vancamp, T. Krigas, Nature 205 (1965) 698-699. 
[3] A. Bergamo, G. Stocco, B. Gava, M. Cocchietto, E. Alessio, B. Serli, E. Lengo, G. Sava, J. Pharmacol. Exp. Ther. 305 (2003) 725-732.

[4] I. Berger, M. Hanif, A.A. Nazarov, C.G. Hartinger CG, R.O. John, M.L. Kuznetsov, M. Groessl, F. Schmitt, O. Zava, F. Biba, V.B. Arion, M. Galanski, M.A. Jakupec, L. Juillerat-Jeanneret, P.J. Dyson, B.K. Keppler, Chemistry 14 (2008) 9046-9057.

[5] C.G. Hartinger, M.A. Jakupec, S. Zorbas-Seifried, M. Groessl, A. Egger, W. Berger, H. Zorbas, P.J. Dyson, B.K. Keppler, Chem. Biodivers. 5 (2008) 2140-2155.

[6] G. Sava, G. Jaouen, E.A. Hillard, A. Bergamo, Dalton Trans. 41 (2012) 8226-8234.

[7] G. Gasser, L. Ott, N. Metzler-Nolte, J. Med. Chem. 54 (2011) 3-25.

[8] C. Biot, G. Glorian, L.A. Maciejewski, J.S. Brocard, J. Med. Chem. 40 (1997) 3715-3718.

[9] S. Top, J. Tang, A. Vessières, D. Carrez, C. Provot, G. Jaouen, Chem. Commun. 8 (1996) 955-956.

[10] S. Top, B. Dauer, J. Vaissermann, G. Jaouen, J. Organomet. Chem. 541 (1997) 355-361.

[11] M. Gormen, P. Pigeon, S. Top, E.A. Hillard, M. Huché, C. Hartinger, F. de Montigny, M.A. Plamont, A. Vessières, G. Jaouen, ChemMedChem 5 (2010) 2039-2050.

[12] A. Vessières, S. Top, P. Pigeon, E. Hillard, L. Boubeker, D. Spera, G. Jaouen, J. Med. Chem. 48 (2005) 3937-3940.

[13] D. Plazuk, A. Vessières, E.A. Hillard, O. Buriez, E. Labbé, P. Pigeon, M.A. Plamont, C. Amatore, J. Zakrzewski, G. Jaouen, J. Med. Chem. 52 (2009) 4964-4967. 
[14] I. Zanellato, J.M. Heldt, A. Vessières, G. Jaouen, D. Osella, Inorg. Chim. Acta 362 (2009) 4037-4042.

[15] J.C. Acosta, J. Gil, Trends Cell Biol. 22 (2012) 211-219.

[16] D. Lamoral-Theys, A. Andolfi, G. Van Goietsenoven, A. Cimmino, B. Le Calvé, N. Wauthoz, V. Megalizzi, T. Gras, C. Bruyère, J. Dubois, V. Mathieu, A. Kornienko, R. Kiss, A. Evidente, J. Med. Chem. 52 (2009) 6244-6256.

[17] V. Mathieu, E.M. de Lassalle, J. Toelen, T. Mohr, A. Bellahcène, G. Van Goietsenoven, T. Verschuere, C. Bouzin, Z. Debyser, S. De Vleeschouwer, S. Van Gool, F. Poirier, V. Castronovo, R. Kiss, O. Feron, J. Invest. Dermatol. 132 (2012) 2245-2254.

[18] V. Mathieu, M. Le Mercier, N. De Neve, S. Sauvage, T. Gras, I. Roland, F. Lefranc, R. Kiss, J. Invest. Dermatol. 127 (2007) 2399-2410.

[19] F. Branle, F. Lefranc, I. Camby, J. Jeuken, A. Geurts-Moespot, S. Sprenger, F. Sweep, R. Kiss, I. Salmon, Cancer 95 (2002) 641-655.

[20] F. Lefranc, G. Nuzzo, N.A. Hamdy, I. Fakhr, L. Moreno, Y. Banuls, G. Van Goietsenoven, G. Villani, V. Mathieu, R. Van Soest, R. Kiss, M.C. Ciavatta, J. Nat. Prod. 76 (2013) 1541-1547.

[21] P. Yaswen, J. Campisi, Cell 128 (2007) 233-234.

[22] F. Rodier, J. Campisi, J. Cell Biol. 192 (2011) 547-556.

[23] T. Kuilman, C. Michaloglou, L.C. Vredeveld, S. Douma, R. van Doorn, C.J. Desmet, L.A. Aarden, W.J. Mooi, D.S. Peeper, Cell 133 (2008) 1019-1031. 
[24] Z. Novakova, S. Hubackova, M. Kosar, L. Janderova-Rossmeislova, J. Dobrovolna, P. Vasicova, M. Vancurova, Z. Horejsi, P. Hozak, J. Bartek, Z. Hodny, Oncogene 29 (2010) 273-284.

[25] J.C. Acosta, A. Banito, T.Wuestefeld, A. Georgilis, P. Janich, J.P. Morton, D. Athineos, T. W. Kang, F. Lasitschka, M. Andrulis, G. Pascual, K.J. Morris, S. Khan, H. Jin, G. Dharmalingam, A.P. Snijders, T. Carroll, D. Capper, C. Pritchard, G.J. Inman, T. Longerich, O.J. Sansom, S.A. Benitah, L. Zender, J. Gil, Nat. Cell Biol. 15 (2013) 978990.

[26] T. Tchkonia, Y. Zhu, J. van Deursen, J. Campisi, J.L. Kirkland, J. Clin. Invest. 123 (2013) 966-972.

[27] J.C. Acosta, A. O’Loghlen, A. Banito, M.V. Guijarro, A. Augert, S. Raguz, M. Fumagalli, M. Da Costa, C. Brown, N. Popov, Y. Takatsu, J. Melamed, F. d'Adda di Fagagna, D. Bernard, E. Hernando, J. Gil, Cell 133 (2008) 1006-1018.

[28] H. Khalaf, J. Jass, P.E. Olsson, BMC Immunol. 11 (2010) 26.

[29] V.C. Foletta, D.H. Segal, D.R. Cohen, J. Leukoc. Biol. 63 (1998) 139-152.

[30] M.C. Velarde, J.M. Flynn, N.U. Day, S. Melov, J. Campisi, Aging 4 (2012) 3-12.

[31] A. Rebbaa, X. Zheng, P.M. Chou, B.L. Mirkin, Oncogene 22 (2003) 2805-2811.

[32] C.A. Schmitt, Biochim. Biophys. Acta 1775 (2007) 5-20.

[33] J.A. Ewald, J.A. Desotelle, G. Wilding, D.F. Jarrard, J. Natl. Cancer Inst. 102 (2010) $1536-1546$ 
[34] A. Rebbaa, Cancer Lett. 219 (2005) 1-13.

[35] Q. Yan, N. Wajapeyee, Cancer Biol. Ther. 9 (2010) 166-175.

[36] A. Vessières, C. Corbet, J.M. Heldt, N. Lories, N. Jouy, I. Laios, G. Leclercq, G. Jaouen, R. A. Toillon, J. Inorg. Biochem. 104 (2010) 503-511.

[37] Q. Michard, G. Jaouen, A. Vessieres, B.A. Bernard, J. Inorg. Biochem. 102 (2008) 19801985.

[38] S. Top, A. Vessières, C. Cabestaing, I. Laios, G. Leclercq, C. Provot, G. Jaouen, J. Organomet. Chem. 637-9 (2001) 500-506.

[39] L.L. Song, F. Alimirah, R. Panchanathan, H. Xin, D. Choubey, Mol. Cancer Res. 6 (2008) 1732-1741.

[40] J.J. Huck, M. Zhang, A. McDonald, D. Bowman, K.M. Hoar, B. Stringer, J. Ecsedy, M.G. Manfredi, M.L. Hyer, Mol. Cancer Res. 8 (2010) 373-384.

[41] X. Zheng, P.M. Chou, B.L. Mirkin, A. Rebbaa, Cancer Res. 64 (2004) 1773-1780.

[42] E. Allard, C. Passirani, E. Garcion, P. Pigeon, A. Vessières, G. Jaouen, J.P. Benoit, J. Control. Release 130 (2008) 146-153.

[43] A.L. Lainé, A. Clavreul, A. Rousseau, C. Tétaud, A. Vessières, E. Garcion, G. Jaouen, L. Aubert, M. Guilbert, J.P. Benoit, R.A. Toillon, C. Passirani, Nanomedicine (2014), http://dx.doi.org/10.1016/j.nano.2014.05.002 (in press). 